\title{
Jakarta Athletics Training during the COVID-19
}

\author{
Aisya Kemala, Khurotul Aini*, Elly Diana Mamesah \\ Department of Physical Education and Health Recreation, Islamic University 45 of Bekasi, 17113, Bekasi, Indonesia
}

Received September 22, 2020; Revised November 30, 2020; Accepted December 22, 2020

\section{Cite This Paper in the following Citation Styles}

(a): [1] Aisya Kemala, Khurotul Aini, Elly Diana Mamesah, "Jakarta Athletics Training during the COVID-19," International Journal of Human Movement and Sports Sciences, Vol. 8, No. 6A, pp. 57-62, 2020. DOI: 10.13189/saj.2020.080710.

(b): Aisya Kemala, Khurotul Aini, Elly Diana Mamesah (2020). Jakarta Athletics Training during the COVID-19. International Journal of Human Movement and Sports Sciences, 8(6A), 57-62. DOI: 10.13189/saj.2020.080710.

Copyright $\bigcirc 2020$ by authors, all rights reserved. Authors agree that this article remains permanently open access under the terms of the Creative Commons Attribution License 4.0 International License

\begin{abstract}
In 2019, all countries experience the corona virus including Indonesia. The spread of the Covid-19 virus outbreak caused obstacles in the athletics training process. This study used a Google form help questionnaire by asking 10 questions to 104 Elite athletes respondents in DKI Jakarta. The results showed $100 \%$ were athletes in DKI, as many as $65.4 \%$ stated that athletes experienced co-19 effects. As many as $73.1 \%$ said exercise could still be done during the outbreak, $76.9 \%$ of athletes stated that the training program was conducted well online. $26.9 \%$ respondents said the exercise was done online with the trainer. As many as $87.4 \%$ of athletes knew the training procedures online $25 \%$ had difficulty training with online trainers; $34.6 \%$ did not always and $40.4 \%$ had no difficulties. $64.4 \%$ of respondents stated online exercises made the training process easier and $35.6 \%$ said there were no obstacles. Barriers to equipment availability are the most dominant experienced by athletes. The results found that online training is suitable for athletes to use in the new normal era.
\end{abstract}

Keywords Athletic, Athlete, COVID-19

\section{Introduction}

During the pandemic, the results of the study stated that community activities were more sedentary, resulting in physical inactivity [1]. This virus can spread by close contact, which includes large droplet spray and inhalation of microscopic droplets, and by indirect contact via contaminated objects[2]. World Health Organization (WHO) has developed a strategy for interruption of human-human contact, isolation of patients at an early stage, identification and reduction of transmission from animal sources, address of the important mystery about the virus and accelerate research, communicate information properly to the public and minimize social and economic impacts [3]. 


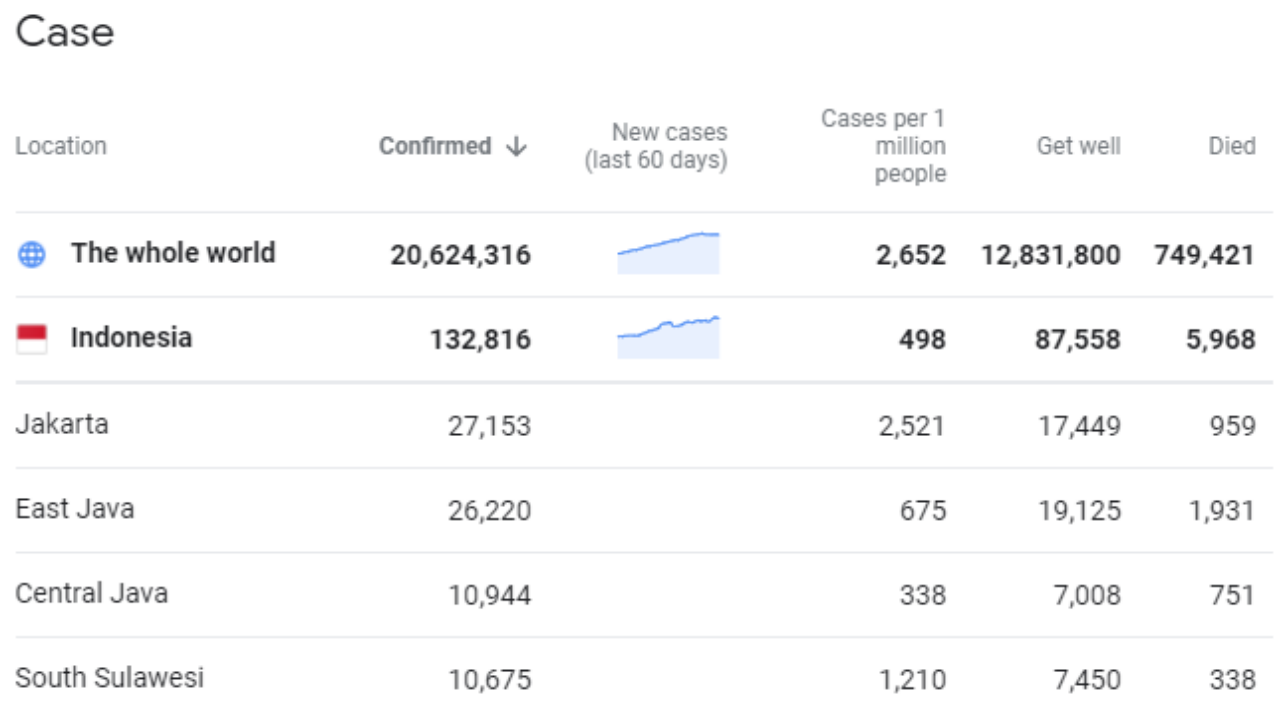

https://news.google.com/covid19/map?hl=id\&mid=\%2Fm\%2F03ryn\&gl=ID\&ceid=ID\%3Aid

Figure 1. Data on covid-19 cases in Indonesia,

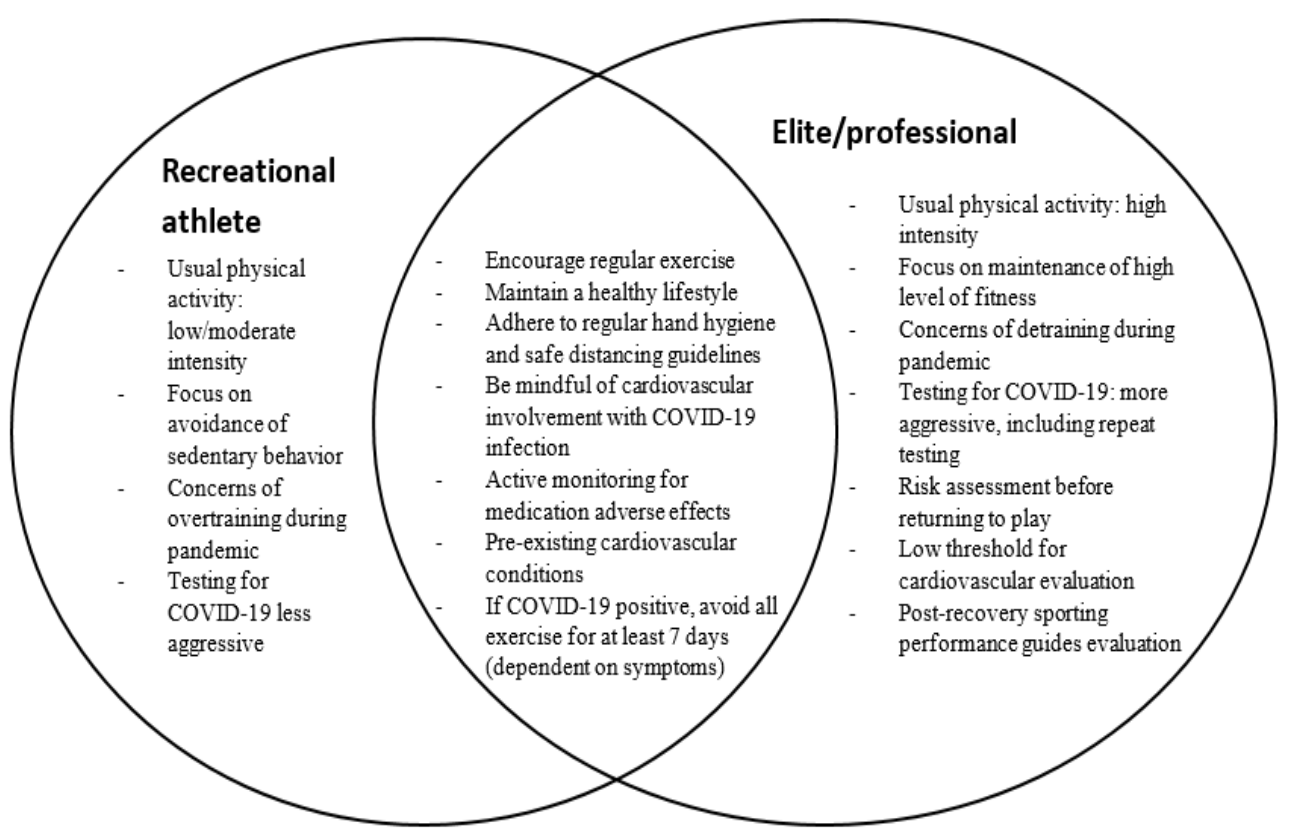

Figure 2. Considerations for sport and exercise amidst the Covid-19 pandemic

Confirmed data as of August 13, 2020, as many as 132,816 Covid cases in Indonesia were confirmed and 27,153 cases occurred in Jakarta, 17,449 were declared cured and 959 died. The highest confirmed cases of Covid-19 occurred in the Jakarta area than in other regions in Indonesia, so that community activities outside the home need to be reduced. Sports activities are mostly carried out outdoors or in open spaces and require a wide scope of space such as fields and buildings which are places for mass gathering or crowds. The closure of all sports facilities forced everyone to do sports at home with limited facilities and infrastructure. The activity of doing sports at home is usually called TFH (Training From
Home). TFH can be done alone or with a companion such as a teacher or trainer. The importance of awareness of healthy living during the Covid 19 pandemic makes everyone take the time in the morning to sunbathe, adjust a healthy diet and do physical activity at home. This is an effort to keep the body's immune system stable and avoid the spread of the Covid 19 virus. Another important issue is that we cannot exclude that Covid-19 infection can cause chronic health consequences [4]. The considerations for sports actors, whether recreational athletes or elite athletes during the pandemic [5] can be seen in Figure 2 above:

This consideration is certainly important for 
professional athletes to maintain performance even in times of a pandemic. The development of achievement in the scope of DKI Jakarta Province is carried out in several phases, starting from the pre-adolescent, adolescent, junior to adult stages. Acting as an athlete has a responsibility to keep training in this pandemic. The coaching carried out is divided into several phases according to the age category, both from the Sports Club Level, POPB (Continuous Sports

Training Center) which is intended for Athletes aged under 14 years, PPOP (Student Sports Training Center) who is under 17 years old, PPLM (Central Student Training Education) aged 18-24 years and adult athlete level at PELATDA (Regional Training Center). It is likely that the transition from junior to adult level in high performance sport is a complex process that involves a unique mix of genetic and environmental influences [6]

So it is precisely the development of achievements in the Athletic Branch in DKI Jakarta Province from adolescence to Adulthood aims to provide the best performance. It is not surprising that the DKI Jakarta Province has become a barometer of the progress of sports achievements in Indonesia. Of course, it is not only the government that is fully responsible for the achievements, but the cooperation between coaches and athletes which plays a very important role in determining sports achievements in Indonesia. Applying such training program for adolescent athletes is certainly different from the training portion for adult athletes, It is recommended that young athletes keep training diaries not only with the view of understanding their training loads but also to understand the loading implications of their attendance, performance, and health [7]. So that giving different volume, intensity and training program items is necessary because the growth and development of the physiology of adolescent and adult athletes is different, and the age of training is also the reason why the provision of training portions is different. Evaluating training monitoring data is crucial to ensure that athletes are exposed to sufficient training to prepare them for the requirements of competition, whilst ensuring the athletes are appropriately adapting to the training program [8]. Social support is also needed by athletes to support training performance to avoid decreasing athlete's performance. The results of research conducted by the results obtained will be the level of urgency of the coach's social support to the positive feedback perception and development of athletes during the competition [9].

The implementation of TFH of an athlete must be supervised by their respective coaches, so that the training program can be monitored and evaluated directly through electronic media. The relationship between coaches and athletes is a very close relationship, like the relationship between parents and children, brothers and sisters, even like siblings. It is believed that such a methodological strategy would allow us to more clearly determine how the coach's perspective influences their athlete's perceptions of the coach athlete relationship as well as their ensuing subjective well-being [10]. The role of online methods is considered good and effective for athletes and coaches can provide training programs and evaluate movements through online such as Zoom, Google Meet or any media that can be done live or in person.

Training monitoring is about keeping track of what athletes accomplish in training, for the purpose of improving the interaction between coach and athlete [11]. Of course there are many obstacles that will be faced by athletes, including deteriorating physical condition, difficulties in facilities and infrastructure to nutrition problems. In this condition, athletes must be able to exercise independently and be self-disciplined, the role of the coach is of course not easy, especially in making a varied training program that can make athletes not get bored and maintain body condition to stay in shape. Some of the problems that arise from Covid-19 in athlete training activities such as no competition, no group training, in some countries there is no outdoor training and no doping tests[12]. The government's decision to cancel all sports events by the end of this year has made athletes only undergo training programs that are maintenance or maintaining body condition. Unable to burn the exercise program because there is still a corona virus everywhere and worrying that heavy training will make the athlete's body's physical condition drop / body immunity decrease so that it is easy to catch viruses / bacteria.

The pandemic has demonstrated the importance of public health. Individual and community actions influence health outcomes. Local protection is used to protect patients and health staff, while regional public health is carried out by planning measures to prevent transmission of the virus [13]. The COVID-19 virus can be transmitted by close contact through respiratory droplets (such as coughing) and by fomites (any inanimate object or substance capable of absorbing, retaining, and transporting contagious or infectious organisms) and COVID-19 can persist on inanimate surfaces such as metal, glass, or plastic for up to 9 days if there is no inactivation by surface disinfection procedures. Given this alarming scenario, a strategy to effectively combat COVID-19 is to maintain physical distance from other people, a term commonly referred to as social distancing [14] The habit of maintaining personal hygiene and health creates new habits for Indonesian athletic athletes, Covid has changed human health habits which require the introduction of a health care system to create a new normal [13]. Activities in normal new activities certainly experience changes in training activities. Covid 19 has caused a lot of harm to athletes. For athletes, significant reduction in training and loss of physical performance capacity can mean loss of competitiveness upon returning 
to competition [14]. It's necessary to collect data on training for athletes in the new normal era at this time.

\section{Research Methods}

In this study using descriptive qualitative research methods that are using Google form help questionnaire. Data analysis applied percentage techniques. The data were collected from research subjects with a total of 104 respondents conducted on 12-16 June 2020. The data collection technique was done by giving a questionnaire to all respondents via Google form. The following is part of the instrument, including: (1) origin athlete and (2) online exercise.

\section{Result}

Based on the results of collecting a questionnaire via Google Form, the following results were obtained:

\subsection{Origin of Athletes}

Distribution of the origin of the athlete's training center is presented in Figure 3 below:

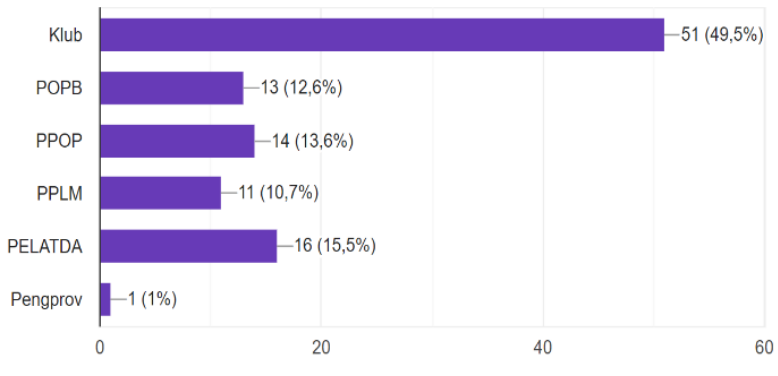

Figure 3. Distribution of origin athlete training center

The distribution of data in Figure 3 shows that $49.5 \%$ of respondents came from clubs, $12.6 \%$ from the Center for Continuing Development (POPB), $13.6 \%$ from the Student Sports Training Center (PPOP), 10.7\% from the Student Training Center. (PPLM), 15.5\% from Regional Training (Pelatda) and 1\% from DKI Pengprov

\subsection{Online Exercise}

Several other aspects included in the questionnaire for athletes in athletic sports are about online exercise, which are obtained in the table 1 .

According to table 1 , the respondents in this study were professional athletic athletes who were registered under the auspices of the DKI Jakarta Provincial Government, from the beginner school to university. The impact of Covid-19 on the training process shows that $65.4 \%$ stated that Covid-19 had an impact on the athlete profession and $34.6 \%$ stated that Covid-19 had no impact on the athlete's profession. the results obtained were $73.1 \%$ stated that they had done exercises online and $22.1 \%$ stated that sometimes the exercises were done online. As many as $26.9 \%$ stated that the training material has been carried out well, $52.9 \%$ stated that sometimes the material was presented well and $20.2 \%$ stated that the training material was not conveyed properly online. In carrying out daily exercises accompanied by a trainer online, $26 \%$ Respondents stated that daily exercises were done online with the coach, $52.9 \%$ sometimes and $20.2 \%$ did not. $87.4 \%$ of athletes have already known online training procedures and $12.6 \%$ have not known online training procedures. $64.4 \%$ Respondents stated that online made the training process easier and $35.6 \%$ said they did not. The finding revealed that the implementation of athletic training routine in DKI Jakarta during pandemic period has already been going well. however this requires refinement of social media as a liaison between coaches and athletes [15]. The results of other studies suggest that the use of social media continuously can reduce the aim of the exercise, so that the use of social media must be improved for better quality.

Table 1. Specific data of Column/Row

\begin{tabular}{|c|c|c|c|c|}
\hline \multirow{2}{*}{ No } & Aspects & \multicolumn{2}{|c|}{ Respondents' answer } \\
\cline { 3 - 5 } & & Yes & No & Sometimes \\
\hline 1 & Respondent profile & $100 \%$ & & \\
\hline 2 & $\begin{array}{c}\text { The impact of covid-19 } \\
\text { on the professional } \\
\text { athlete }\end{array}$ & $65.4 \%$ & $34.6 \%$ & \\
\hline 3 & $\begin{array}{c}\text { Distribution of online } \\
\text { exercises in the new era }\end{array}$ & $73.1 \%$ & $22.1 \%$ \\
\hline 5 & $\begin{array}{c}\text { Distribution of online } \\
\text { exercise material } \\
\text { delivery }\end{array}$ & $26.9 \%$ & $20.2 \%$ & $52.9 \%$ \\
\hline 6 & $\begin{array}{c}\text { Online daily exercises } \\
\text { extribution of online }\end{array}$ & $26 \%$ & $20.2 \%$ & $52.9 \%$ \\
\hline 7 & $\begin{array}{c}\text { Distribution of ease of } \\
\text { exercise when done } \\
\text { online }\end{array}$ & $64.4 \%$ & $35.6 \%$ & \\
\hline
\end{tabular}

\section{Discussion}

Based on the results obtained, it is known that athletic training activities for athletes in the DKI Jakarta Province in the new normal period can still be done both offline and online. In online training, athletes are assisted by a coach virtually even though there are various obstacles during training. The offline / direct implementation is carried out by paying attention to health protocols, such as wearing masks, maintaining distance and washing hands. Covid has forced people to keep their distance and prevent the spread by continuing to exercise and staying active at home [16]. Sports events that are almost entirely conducted on a competitive basis are delayed at all levels [17]. This is because there is a strategy from a public 
health program to anticipate the spread of Covid-19 through limiting interactions between individuals [18].

Sports activities that have great potential to create mass groups are now transformed into activities that are carried out independently

[19]. Sports activities at home cause many athlete problems such as career disruption, social communication, disruption of effective training and postponement of race events [20]. To minimize the pressure faced by athletes, it is necessary to recommend physical activity that can be done in their respective homes. During a pandemic WHO recommends 60 minutes/day of moderate-to-vigorous physical exercise activity for children aged 6-17 years, and vigorous 75 minutes / week or 150 minutes / week moderate physical activity for adults and adults, including 3 and 2 days / week, respectively, by strengthening muscles and bones [21]. In activities in the new era, it is normal for athletes to do physical activity outside the home because of the need for standard sports facilities and to support the athlete's cognitive and affective conditions. Participants reported the number of minutes spent in outdoor physical activity per week along with the importance of nature and whether the activity occurred in a natural environment. Moreover, a certain item of the natural entanglement scale is utilized based on its impact on physical activity behavior. The natural connectedness scale asks questions about natural relationships in the context of measuring a person's cognitive and physical affective relationships with nature[22]. In training activities in the new normal period, coaches and athletes must follow the recommended health protocols.

Using effective hand hygiene practices to prevent and control infection [23]. Simulation facilities (SF) should provide appropriate hand sanitizing agents. For washing hands, plain soap is sufficient. In the absence of water, alcohol-based cleaners can be used as recommended by the World Health Organization (WHO). The hand rub formulation can also be prepared by SF according to WHO guidelines. Instructions on how to rub and wash hands provided and posters published by WHO can be used. Training activities during the Covid-19 period no longer aim to achieve achievements, now they have switched goals to maintain physical condition, reduce injuries, maintain movement quality and maintain the psychological condition of athletes [5]. The difference in the need for exercise for recreational athletes and professional athletes is very different during a pandemic. Professional athletes need to prepare themselves for upcoming race events and need access to standard sports facilities, a team of professional coaches which results in the need for physical activity outside the home [2], thus offline training is also required by professional athletes.

For professional athletes, towards the new normal that will be implemented by the government, the training program provided by the coaches is still in general preparation with of maintaining performance. Meanwhile, special training programs, pre-competition and competition cannot be implemented. This is because there are no events held this year. Athlete training programs that are usually carried out at home in the new normal can already be done at the stadium but in a limited number of athletes and a limited time. Meanwhile, the health protocol must still be applied.

\section{Conclusions}

The purpose of this study was to find the suitability of sports training using online training for athletes in DKI Jakarta, Indonesia in the normal new era. The results showed that in the new normal period which is very necessary to maintain personal health and the environment, it shows that online and offline training activities can still be carried out properly by athletes, although there are some problems, if done online there are some difficulties such as limited quota, difficulty making movements which is true if you do not receive direction from the trainer, limited exercise equipment at home and must use health protocols when done offline or face to face in the field. Some training problems that are needed by athletes must be reviewed by the coach so that current activity deficiencies can be properly resolved.

\section{Acknowledgments}

We are grateful to the research subjects, namely athletes in athletics DKI Jakarta and the Islamic University 45 Bekasi who have supported this research.

\section{REFERENCES}

[1] B. Constandt, E. Thibaut, V. De Bosscher, J. Scheerder, M. Ricour, and A. Willem, "Exercising in times of lockdown: An analysis of the impact of COVID-19 on levels and patterns of exercise among adults in Belgium," Int. $J$. Environ. Res. Public Health, vol. 17, no. 11, pp. 1-10, 2020.

[2] B. Blocken, T. van Druenen, T. van Hooff, P. A. Verstappen, T. Marchal, and L. C. Marr, "Can indoor sports centers be allowed to re-open during the COVID-19 pandemic based on a certificate of equivalence?," Build. Environ., vol. 180, no. May, p. 107022, 2020.

[3] B. Vellingiri et al., "COVID-19: A promising cure for the global panic," Sci. Total Environ., vol. 725, p. 138277, 2020.

[4] A. Corsini, G. N. Bisciotti, C. Eirale, and P. Volpi, "Football cannot restart soon during the COVID-19 emergency! A critical perspective from the Italian experience and a call for action," British Journal of Sports Medicine. 2020.

[5] C. Latella and G. G. Haff, "Global Challenges of Being a Strength Athlete during a Pandemic: Impacts and 
Sports-Specific Training Considerations and Recommendations," Sports, vol. 8, no. 7, p. 100, 2020.

[6] S. C. Hollings, C. J. Mallett, and P. A. Hume, "The transition from elite junior track-and-field athlete to successful adult athlete: Why some do, why others don't," Int. J. Sport. Sci. Coach., 2014.

[7] P. C. Bourdon et al., "Monitoring athlete training loads: Consensus statement," Int. J. Sports Physiol. Perform., 2017.

[8] H. R. Thornton, J. A. Delaney, G. M. Duthie, and B. J. Dascombe, "Developing athlete monitoring systems in team sports: Data analysis and visualization," Int. J. Sports Physiol. Perform., 2019.

[9] J. Elvis Hagan Jnr, E. Wilson Ansah, D. Pollmann, and T. Schack, "Elite Student-Athletes' Perceptions of Coaches' Behavior during the 23rd World Universiade Games in Kazan, Russia," International Journal of Human Movement and Sports Sciences, vol. 5, no. 4, pp. 68-76, 2017.

[10] M. A. K. Lafrenière, S. Jowett, R. J. Vallerand, and N. Carbonneau, "Passion for coaching and the quality of the coach-athlete relationship: The mediating role of coaching behaviors," Psychol. Sport Exerc., 2011.

[11] C. Foster, J. A. Rodriguez-Marroyo, and J. J. De Koning, "Monitoring training loads: The past, the present, and the future," International Journal of Sports Physiology and Performance. 2017.

[12] H. Wackerhage et al., "Sport, exercise and COVID-19, the disease caused by the SARS-CoV-2 coronavirus," Dtsch. Zeitschrift für Sport. J. Sport. Med., vol. 71, no. 5, pp. E1E12, 2020

[13] S. Duckett, "What should primary care look like after the COVID-19 pandemic?," Aust. J. Prim. Health, vol. 26, no. 3, pp. 207-211, 2020.

[14] L. V. Andreato, D. R. Coimbra, and A. Andrade,
"Challenges to Athletes During the Home Confinement Caused by the COVID-19 Pandemic," Strength Cond. J., vol. 42 , no. 3 , pp. $1-5,2020$.

[15] K. Zhang and Y. Melannie Zhan, "Research on Continued Use of Sport-related Social Application: Taking WeRun as an Example," International Journal of Human Movement and Sports Sciences, vol. 5, no. 4, pp. 57-67, 2017.

[16] G. Maugeri et al., "The impact of physical activity on psychological health during Covid-19 pandemic in Italy," Heliyon, vol. 6, no. 6, p. e04315, 2020.

[17] A. B. Evans et al., "Sport in the face of the COVID-19 pandemic: towards an agenda for research in the sociology of sport,” Eur. J. Sport Soc., vol. 17, no. 2, pp. 85-95, 2020.

[18] A. L. Kelly, K. Erickson, and J. Turnnidge, "Youth sport in the time of COVID-19: considerations for researchers and practitioners," Manag. Sport Leis., vol. 0, no. 0, pp. 1-11, 2020.

[19] D. Parnell, P. Widdop, A. Bond, and R. Wilson, "COVID-19, networks and sport," Manag. Sport Leis., vol. 0, no. 0, pp. 17, 2020.

[20] R. Schinke, A. Papaioannou, K. Henriksen, G. Si, L. Zhang, and P. Haberl, "Sport psychology services to high performance athletes during COVID-19," Int. J. Sport Exerc. Psychol., vol. 18, no. 3, pp. 269-272, 2020.

[21] A. Hammami, B. Harrabi, M. Mohr, and P. Krustrup, "Physical activity and coronavirus disease 2019 (COVID-19): specific recommendations for home-based physical training," Manag. Sport Leis., vol. 0, no. 0, pp. 1-6, 2020.

[22] J. Dekker, B. M. Buurman, and M. van der Leeden, "Exercise in people with comorbidity or multimorbidity," Heal. Psychol., 2019.

[23] M. D. Hillier, "Using effective hand hygiene practice to prevent and control infection," Nurs. Stand., 2020. 